
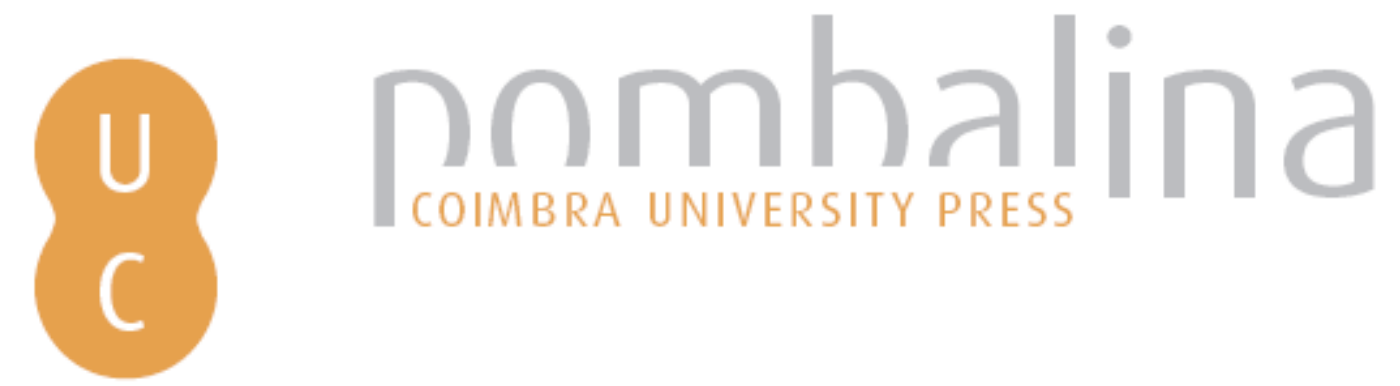

\title{
Francisco Miranda da Costa Lobo na vanguarda do cinema astronómico internacional
}

Autor(es): $\quad$ Bonifácio, Vitor; Malaquias, Isabel; Fernandes, João

Publicado por: Imprensa da Universidade de Coimbra

URL

persistente: URI:http://hdl.handle.net/10316.2/38454

DOI: $\quad$ DOI:http://dx.doi.org/10.14195/978-989-26-0764-1_18

Accessed : $\quad$ 26-Apr-2023 14:42:40

A navegação consulta e descarregamento dos títulos inseridos nas Bibliotecas Digitais UC Digitalis, UC Pombalina e UC Impactum, pressupõem a aceitação plena e sem reservas dos Termos e Condições de Uso destas Bibliotecas Digitais, disponíveis em https://digitalis.uc.pt/pt-pt/termos.

Conforme exposto nos referidos Termos e Condições de Uso, o descarregamento de títulos de acesso restrito requer uma licença válida de autorização devendo o utilizador aceder ao(s) documento(s) a partir de um endereço de IP da instituição detentora da supramencionada licença.

Ao utilizador é apenas permitido o descarregamento para uso pessoal, pelo que o emprego do(s) título(s) descarregado(s) para outro fim, designadamente comercial, carece de autorização do respetivo autor ou editor da obra.

Na medida em que todas as obras da UC Digitalis se encontram protegidas pelo Código do Direito de Autor e Direitos Conexos e demais legislação aplicável, toda a cópia, parcial ou total, deste documento, nos casos em que é legalmente admitida, deverá conter ou fazer-se acompanhar por este aviso.

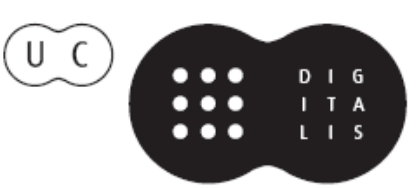


${ }^{1}$ Departamento de Física, Centro de Investigação "Didáctica e Tecnologia na Formação de Formadores", Universidade de Aveiro

${ }^{2}$ CGUC, Departamento de Matemática e Observatório Astronómico,

Universidade de Coimbra

vitor.bonifacio@ua.pt; imalaquias@ua.pt; jmfernan@mat.uc.pt

\section{Francisco Miranda da Costa Lobo na Vanguarda do Cinema Astronómico Internacional}

\section{Vitor Bonifácio ${ }^{1}$, Isabel Malaquias ${ }^{1}$ e João Fernandes ${ }^{2}$}

Jules Janssen desenvolveu, para a observação do trânsito de Vénus de 1874, aquele que é considerado o primeiro precursor das modernas câmaras de filmar. No entanto, e apesar desta linhagem, nas primeiras décadas após a apresentação pública do cinema pelos irmãos Lumière, em 1895, a nova técnica raramente foi utilizada em observações astronómicas. Apenas em 1912 se assistiu à utilização de várias máquinas de filmar para registar o eclipse solar de 17 de Abril. Uma destas máquinas acompanhava a expedição liderada por Francisco Miranda da Costa Lobo, professor e astrónomo da Universidade de Coimbra. Através da análise do filme obtido, Costa Lobo formulou a primeira hipótese astronómica - um ligeiro achatamento polar da Lua baseado apenas num registo cinematográfico. No debate que se seguiu, a comunidade astronómica rejeitou esta hipótese, apesar de, na época, os resultados obtidos pelos vários observadores serem inconclusivos. Nas décadas seguintes, Costa Lobo procurou filmar, sem sucesso, outros eclipses solares.

Neste artigo, pormenorizamos as várias tentativas efectuadas por Costa Lobo para cinematografar os eclipses solares de Abril de 1912, Agosto de 1914 e Junho de 1927. Analisamos os resultados obtidos e estudamos o seu impacto na comunidade internacional. Concluímos que Costa Lobo foi um pioneiro da cinematografia astronómica a nível internacional.

\section{INTRODUÇÃO}

As histórias da fotografia, da cinematografia e da astronomia estão intrinsecamente ligadas pela apresentação pública do daguerreótipo por François Arago (1786-1853), em 19 de agosto de 1839, e pelo revólver fotográfico inventado por Jules Janssen para capturar o trânsito de Vénus em 1873 (1824-1907) (ARAGO 1839; JANSSEN 1873; TOSI 2005).

O revólver fotográfico foi o primeiro instrumento destinado a obter, automaticamente, uma série de fotografias. Após ser accionado, o mecanismo obtinha uma série de fotografias cujas características, bem como o intervalo de tempo entre elas, se encontravam pré-determinadas. O revólver fotográfico registava 48 imagens em 
72 segundos num único daguerreótipo através de um mecanismo de relógio. Desta forma, Janssen pretendia determinar com elevada precisão os instantes dos contactos aparentes entre Vénus e o Sol e, consequentemente, melhorar o valor da unidade astronómica, isto é, a distância entre a Terra e o Sol. Apesar de terem sido utilizados nove revólveres na observação do trânsito de 1874, os resultados foram uma desilusão. De tal forma que, nos anos seguintes, conhecem-se apenas duas referências à utilização deste instrumento em observações astronómicas. Na expedição de observação do eclipse solar de 5 de Abril de 1875, nas ilhas Nicobar (Golfo de Benguela) sob a direcção de James Waterhouse (1842-1922) um revólver de estilo inglês foi utilizado, acoplado a um espectroscópio. No início da década de 80 , Janssen utilizou, no observatório de Meudon, um revólver no registo da granulação solar. No primeiro caso, a observação foi impedida pelas condições atmosféricas e, no segundo, não se conhece nem a extensão temporal da experiência nem uma análise das imagens obtidas (LAUNAY E HINGLEY 2005). Apesar destes resultados, o revólver de Janssen inspirou o trabalho de Étienne-Jules Marey (1830-1904), em particular o fuzil fotográfico, constituindo um importante passo no desenvolvimento da câmara de filmar (TOSI 2005). Contudo, e apesar desta linhagem, as câmaras de filmar foram raramente utilizadas em observações astronómicas nos anos imediatamente após a apresentação pública do cinema, pelos irmãos Lumière, em 1895. A primeira tentativa de cinematografar um eclipse solar total ocorreu em 1898 , tendo o primeiro filme astronómico sido obtido durante o eclipse de 28 de Maio de 1900. A reduzida utilização da nova técnica cinematográfica resulta, no nosso entender, da falta de eventos astronómicos adequados, isto é, eventos rápidos que decorram em escalas de tempo de minutos, ou inferiores, e suficientemente brilhantes para poderem serem registados com as películas de baixa sensibilidade existentes na época. Em consequência destes constrangimentos, as primeiras tentativas de cinematografia astronómica concentraram-se no registo de eclipses solares, tendo a primeira utilização de um número importante de câmaras, nove, ocorrido na observação do eclipse de 17 de Abril de 1912.

\section{O INESPERADO RESUltado do ECLIPSE DE 17 DE ABRIL DE 1912}

Num eclipse solar total, o cone de sombra da Lua intersecta a superfície terrestre. Nesta situação um observador localizado dentro do cone de sombra vê o disco da Lua tapar completamente o disco do Sol. Devido aos diferentes diâmetros aparentes, resultantes da variação de distância entre o Sol, a Lua e a Terra, por vezes apenas a segunda folha do cone de sombra intersecta a superfície terrestre. Nesta situação, o vértice do cone de sombra encontra-se acima da superfície terrestre e um observador localizado no interior do círculo de sombra, produzido pela segunda folha do cone, observa um eclipse anular visto que o disco escuro da Lua, na fase máxima, não cobre completamente o disco solar. É ainda possível a ocorrência de um eclipse total ou anular, dependendo da localização geográfica do observador devido, essencialmente, à curvatura da Terra. Estes eclipses são chamados híbridos ou anular-totais.

O eclipse de 17 Abril de 1912 foi, segundo as previsões atuais, um eclipse híbrido no qual a fase de totalidade máxima foi de aproximadamente dois segundos (ESPENAK, 
sem data). Neste tipo de eclipses de curta duração, o vértice do cone de sombra da Lua apenas rasa a superfície terrestre. O eclipse começou por ser anular na América do Sul, passou a total no oceano Atlântico, entrou no continente europeu em Portugal e cruzou o norte de Espanha, antes de passar a anular no golfo da Biscaia. Posteriormente, a faixa de anularidade intersectou França, a Bélgica, Holanda, Alemanha, Letónia e Estónia, terminando o eclipse na Rússia.

As circunstâncias de um dado eclipse podem ser calculadas conhecendo os diâmetros do Sol e da Lua, a sua localização no espaço e o seu movimento em função do tempo. A observação de um eclipse solar permite testar a precisão dos parâmetros utilizados na sua previsão e, em particular, a adequação do modelo utilizado para descrever o movimento da Lua. A partir de 1842, no entanto, a observação de eclipses solares com objectivos astrométricos foi perdendo importância relativamente ao estudo das propriedades físicas das estruturas apenas visíveis durante a fase de totalidade. Por forma a aproveitar estes curtos instantes de totalidade, dezenas de expediçōes astronómicas foram organizadas a regiōes, por vezes remotas, do globo terrestre. Estas expedições constituíram, a par com as de observação dos trânsitos de Vénus de 1874 e 1882, a "grande ciência" astronómica da segunda metade do século XIX e início do século XX. Em contra corrente com estes desenvolvimentos o principal interesse da observação do eclipse de 17 de Abril de 1912 não era astrofísico mas sim astrométrico. Este anacronismo advinha das características muito particulares do eclipse, e, em particular, da sua curtíssima duração. Nesta situação limite, pequenas diferenças nos parâmetros utilizados nas previsões têm consequências importantes.

No início do século XX, as efemérides astronómicas diferiam essencialmente no diâmetro médio angular da Lua utilizado no cálculo das circunstâncias de um dado eclipse. Num eclipse como o de Abril de 1912, isto implicava que, segundo "o American Ephemeris, só na Península será total o eclipse, e segundo o Almanaque de San Fernando, será unicamente anular" (OOM 1912). Isto é, algumas previsões indicavam que o eclipse seria anular, enquanto noutras este seria híbrido. Em consequência dos diferentes parâmetros utilizados, as previsões diferiam na localização e largura da faixa de totalidade. Este facto implicava que, por exemplo na região de Ovar, as faixas de totalidade previstas pelos observatórios de Madrid e Coimbra não se intersectassem. Sendo estes eclipses relativamente raros (entre 1800 e 1912 ocorreram apenas nove eclipses solares, cinco híbridos e quatro anulares, com duração inferior a 7 segundos segundo previsōes atuais) existia um grande interesse na observação astrométrica do eclipse, pois esta iria, em princípio, constringir os diferentes parâmetros utilizados nas previsōes enquanto, simultaneamente, a curta duração, se alguma, da totalidade reduzia o interesse em proceder a estudos astrofísicos (LOBO 1912a; ESPENAK sem data).

O último eclipse solar total cuja faixa de totalidade tinha intersectado o território português ocorrera em 28 de Maio de 1900. Na altura, ficou claro que os meios observacionais ao dispor dos astrónomos nacionais não eram competitivos, quando comparados com os dos seus congéneres estrangeiros, em consequência da falta de investimento em novos equipamentos nas últimas décadas do século XIX. Um retracto da situação portuguesa foi providenciado por Frederico Oom (1864-1930), em 1905, no artigo em que explica a inutilidade de enviar uma expedição científica oficial com o intuito de observar o eclipse solar de agosto desse ano em Espanha: 


\begin{abstract}
"Quem possue caros instrumentos, sómente úteis em eclipses de sol, quem inventou processos novos que tambem só ahi se applicam, e quando duns e doutros ha motivos para esperar mais algum passo no estudo dos phenómenos que acompanham um eclipse total, necessariamente deve ir observá-los, por mais difficuldade ou incertezas que isso possam contrariar. Mas quem nada mais iria fazer do que repetir com escassos recursos o mesmo trabalho que estarão fazendo dezenas de astronomos mais bem municiados para o caso, ou mais competentes como especialistas, nenhuma justificação teria, a não ser que o phenomeno tendo logar no territorio nacional, importa de algum modo o dever de collaborar, escassamente que seja, no seu estudo" (OOM 1905).
\end{abstract}

Entre 1905 e 1912, a astronomia portuguesa não sofreu alterações significativas e não é de estranhar, por isso, que os astrónomos do observatório da Tapada da Ajuda tenham observado um eclipse solar parcial a 17 de Abril em Lisboa. No observatório foram obtidas 237 fotografias do eclipse e medidos os instantes de contacto (RODRIGUES 1912).

Opção diferente tomou Francisco Miranda da Costa Lobo (1864-1945), professor da Universidade de Coimbra e $1 .{ }^{\circ}$ astrónomo do respectivo observatório astronómico. Aproveitando as características especiais do eclipse, Costa Lobo decidiu efectuar uma modesta expedição a Ovar. Pretendendo determinar com precisão a localização da faixa de totalidade, Costa Lobo distribuiu os membros da expedição por 10 estaçóes de observação dispostas ao longo de $6 \mathrm{~km}$ num segmento de recta aproximadamente perpendicular às linhas centrais previstas pelas várias efemérides (LOBO 1912a; 1912c). Este método tinha sido utilizado anteriormente por Airy nos eclipses anulares de 1847 e 1858, e na Argélia no eclipse de 30 de agosto de 1905 (AIRY 1896; FOUCHÉ 1912). Em 1912, os alunos da Escola Politécnica de Paris, distanciados de $100 \mathrm{~m}$, foram distribuídos ao longo de uma linha entre Trappes and Neauphle (CARVALLO 1912).

Os instrumentos ao dispor da expedição eram modestos, estando a estação principal equipada com um pequeno teodolito de Troughton, um helióstato, dois termómetros e um cronómetro, pertencentes à Universidade de Coimbra e duas câmaras emprestadas, uma fotográfica e uma cinematográfica. Foi, precisamente, a utilização deste último aparelho que colocou a observação portuguesa num grupo reduzido de expedições equipadas com este novo meio de aquisição de dados. Seguidamente, apresentamos os resultados obtidos pela expedição, cuja análise detalhada foi recentemente publicada (BONIFÁCIO et al. 2010).

O helióstato enviava a luz solar para uma objectiva de $0,07 \mathrm{~m}$ de abertura, reduzida a $0,03 \mathrm{~m}$ durante a fase de totalidade, e 1,14 $\mathrm{m}$ de distância focal antes desta impressionar o filme na câmara de filmar. A observação foi bem sucedida e durante a fase máxima foram registadas aproximadamente 545 imagens por minuto (LOBO 1912b).

No filme, os grãos de Baily apareciam em 158 imagens (14 s). Costa Lobo reparou que, 45 imagens após o aparecimento do primeiro grão de Baily, estes apareciam apenas em duas regióes diametralmente opostas e aproximadamente perpendiculares ao movimento da Lua, situação essa que se manteve durante 40 imagens, ou seja, 4,4 segundos. Considerando que esta observação correspondia a um achatamento lunar, Costa Lobo estimou os seus limites inferior e superior. Para tal supôs duas condiçôes de visibilidade das contas de Baily na direcção perpendicular ao movimento. Na primeira, as contas visíveis encontravam-se no fundo dos vales lunares. Consequentemente, a diferença entre os dois diâmetros igualava a distância percorrida pela Lua em 4,4 segundos, obtendo-se um limite inferior para o achatamento. Isto assumindo que na 
direcção perpendicular ao movimento ainda se observava o nível mais baixo dos vales lunares, o datum de referência considerado por Costa Lobo. A segunda condição tomava em consideração a existência de montanhas lunares, tornando-se as contas visíveis quando se encontravam a meia altura destas. Costa Lobo considerou que não sendo as montanhas, localizadas nas zonas de interesse, as mais altas da Lua, teriam uma altura de $8 \mathrm{~km}$, as contas ficariam, assim, visíveis quando se encontrassem $4 \mathrm{~km}$ acima do nível mais baixo dos vales lunares. Neste caso a diferença entre os diâmetros anteriores seria $8 \mathrm{~km}$ maior e obtinha-se uma estimativa do limite superior do achatamento. Costa Lobo publica os seus resultados numa comunicação lida na Academia das Ciências de Paris a 20 de Maio de 1912 (LOBO 1912b). Uns meses mais tarde, Costa Lobo recalcula os valores obtidos utilizando uma velocidade da Lua mais realista e admitindo uma nova hipótese para o limite superior do achatamento lunar. Um intervalo de tempo de 13,2 segundos (120 imagens) mediava o aparecimento dos grãos de Baily na zona do segundo contacto e o seu desaparecimento na região do terceiro contacto. Assumindo que o topo das montanhas lunares nas regiōes polares era tangente ao disco aparente do Sol, Costa Lobo obteve o limite superior do achatamento lunar. Os resultados obtidos foram 1/1156 e 1/380 para os limites inferior e superior, respectivamente. $\mathrm{Na}$ ausência de mais observações, Costa Lobo considerou preferível atribuir ao achatamento lunar o valor inferior (LOBO 1912c).

Após o aparecimento da comunicação de Costa Lobo nos Comptes Rendus da Academia das Ciências de Paris, foram publicados pelo menos três outros artigos que discutiam um possível achatamento lunar a partir de dados cinematográficos.

Camille Flammarion (1842-1925), num texto intitulado "Forme de la Lune déduites des observations cinématographiques", que publicou no Bulletin de la Société Astronomique de France de Julho de 1912, no qual incluiu uma reprodução integral do artigo "particularmente interessante" de Costa Lobo, atrás referido, concluiu que o filme obtido por Léon Gaumont (1864-1946) em Grand-Croix confirmava a hipótese do astrónomo português (FLAMMARION 1912b).

Em Julho, Fernand Willaert (1877-1953) publicou uma análise detalhada do filme do eclipse anular por si obtido, em Namur, Bélgica. As imagens revelavam que o anel era mais espesso a norte do que a sul, indicando uma localização do local de observação a norte da linha central e que a espessura, na região sul do anel, era superior à da região equatorial. Este último resultado poderia ser devido a um achatamento da Lua, que, assumindo o Sol como circular, Willaert calculou em $1 / 2050$, isto é, um valor inferior ao de Costa Lobo (LUCAS E WILLAERT, 1912).

Em Setembro, foi apresentada na Academia das Ciências de Paris a análise efectuada por Fred Vlès (1885-1944) ao filme realizado em Cacabelos, Espanha. Comparando a variação temporal da corda que unia os extremos da Lua com as obtidas pela passagem de diferentes figuras geométricas (círculos e elipses) pela frente umas das outras, concluiu que diversas combinações podiam explicar os dados obtidos embora pelo menos um dos corpos celestes tivesse de possuir uma forma não circular. Contudo, uma elipse com o semieixo maior na direcção do movimento da Lua e um Sol circular, a hipótese de Costa Lobo era incompatível com os resultados obtidos (VLĖS 1912).

Ainda em 1912, Costa Lobo publicou um novo artigo em que reanalisava com mais detalhe os resultados do filme obtido em Ovar. Neste, como já referimos, recalculou os limites inferior e superior do achatamento lunar. Eliminou a hipótese da 
diferença observada ser devida a um efeito de uma Lua com a forma de um elipsóide de revolução e eixo maior na direcção Terra-Lua. Por último, da análise da variação do brilho das contas de Baily concluiu a existência de uma camada gasosa no fundo dos vales lunares. É muito provável que este extenso artigo escrito em francês e publicado no primeiro volume da Revista da Universidade de Coimbra tenha tido a sua difusão limitada a alguns leitores nacionais e aos contactos a quem o autor enviou separatas (LOBO 1912c).

Flammarion continuou também a analisar os muitos relatórios de observação do eclipse e, em Novembro, tinha mudado de opiniāo. As observações não eram consequência de um maior diâmetro equatorial da Lua mas sim da irregularidade do perfil lunar (FLAMMARION 1912a). Recentemente analisámos esta questão e concluímos que, tendo em conta as incertezas associadas à dimensão e localização das montanhas da Lua, não era possível estabelecer uma conclusão definitiva na ausência de mais observações (BONIFÁCIO et al. 2010). Costa Lobo sabia que a observação só poderia ser repetida dali a muitos anos:

“por ser indispensável para êsse fim que o eclipse se apresentasse em condições análogas, com o vértice do cone de sombra rasante à superfície da terra, como poderá ter lugar nos próximos eclipses de 3 de janeiro de 1927" (LOBO 1914).

Em contrapartida, a conclusão de Flammarion não questionava a noção estabelecida na comunidade astronómica, de que o disco lunar era, em média, circular não sendo, por isso, de estranhar que as observações cinematográficas efectuadas tenham sido rapidamente esquecidas (BONIFÁCIO et al. 2010).

\section{UMA NOVA OPORTUNIDADE - O ECLIPSE DE 21 DE Agosto de 1914}

Ainda a comunidade científica internacional debatia os diferentes resultados cinematográficos obtidos no mês de Abril anterior, quando ocorreu, a 10 de Outubro de 1912, um novo eclipse solar cuja faixa de totalidade intersectou a América do Sul. Pelo menos oito expedições de cinco países diferentes não foram bem sucedidas devido ao mau tempo. A observação dos três eclipses solares de 1913 era pouco interessante do ponto de vista científico, visto estes serem parciais. O eclipse anular do Sol de 25 de Fevereiro de 1914 seria apenas visível no Oceano Pacífico e na Antárctida. Consequentemente, foi o eclipse de 21 de Agosto de 1914, cuja faixa de totalidade intersectava a Noruega, Suécia, Estónia, Lituânia, Letónia, Bielorrússia e Ucrânia, que voltou a mobilizar os esforços da comunidade astronómica internacional. Em Agosto de 1913, cerca de vinte instituições pretendiam enviar expedições à faixa de totalidade. Um dos astrónomos italianos, presente na Crimeia, contabilizou dezanove expedições de observação efectivamente realizadas, enquanto o director do observatório de Cordoba, na Argentina, referiu vinte e sete expedições planeadas (RICCÒ 1914; PAOLANTONIO sem data).

Costa Lobo pretendeu participar nesta movimentação internacional. Contando com o apoio logístico do astrónomo Nicolae Donici (1874-1956?), que tinha estado em 1912 em Ovar, uma expedição de três pessoas dirigiu-se no fim de Julho para 
a Crimeia. Quinze dias antes, a 10 de Julho, tinham sido enviados por via marítima os instrumentos astronómicos (LOBO 1914).

As condiçôes do eclipse de 21 de agosto de 1914, um eclipse total com uma duração máxima de $2 \mathrm{~m} 14 \mathrm{~s}$, segundo previsões atuais, eram completamente diferentes das do observado em 17 de Abril de 1912 e, em particular, Costa Lobo estava consciente, como já foi anteriormente referido, que não poderia repetir as observações anteriores e, dessa forma, testar a sua hipótese sobre a forma da Lua. No entanto,

"O estudo da variação de aspectos dos grãos de Baily, simétrica nos dois contactos interiores, primeiro brilhantes e depois crepusculares, ou inversamente, [...] poderia ser agora feito, e oferecia particular interesse justificar a hipótese que apresentei para a sua explicação no artigo publicado no vol. I da Revista da Universidade de Coimbra, e mais desenvolvidamente, na memória que tive a honra de apresentar ao congresso realizado em Madrid, em Junho de 1913, pela sociedade para o avanço das sciências de Espanha” (LOBO 1914).

Esta hipótese considerava que a variação do brilho observado das contas de Baily indicava a presença de uma camada gasosa densa nos vales lunares (LOBO 1914, p. 14; LOBO 1915).

Embora no final do século XIX fosse consensual que a Lua não poderia possuir uma atmosfera significativa, pois

- não se observavam nuvens na Lua o que implicava uma atmosfera sempre transparente;

- não se observavam crepúsculos na fronteira entre as superfícies iluminada e escura da Lua;

- as ocultações de corpos celestes pela Lua não indicavam a presença de uma atmosfera lunar;

- não se detetavam diferenças entre os espectros da luz solar directa e da reflectida na superfície lunar; ora se a Lua possuísse uma atmosfera significativa, os gases que a constituíam teriam uma assinatura espectral própria (FLAMMARION 1880).

Debatia-se, ainda, a possível existência de uma camada gasosa no fundo dos vales lunares (FLAMMARION 1880). Esta questão mantinha-se, em 1912, sem uma resposta conclusiva. Por exemplo, uma publicação do observatório de Harvard desse ano concluía, a partir do estudo de ocultaçôes estelares, que a Lua não possuía aparentemente uma atmosfera apreciável a altitudes superiores a uma milha. Sendo, no entanto, esta altitude inferior à de muitas montanhas lunares, as observaçôes não excluíam a existência de uma atmosfera lunar a baixa altitude (KING 1912, p. 203).

Preparando a observação cinematográfica, Costa Lobo decidiu utilizar uma montagem paraláctica para a câmara de filmar por forma a aumentar a estabilidade da imagem no filme cinematográfico. Foi ainda

“estabelecida uma disposição que, aproveitando um cronómetro de tempo médio com interruptor de meio segundo e um cronógrafo permitia registar as épocas com uma aproximação de duas centésimas de segundo. Com êste aparelho, que designarei por cinéliocronógrafo, seriam obtidas imagens do Sol de cêrca de 11 milímetros de diâmetro. Como a film preparada 
para carregar a câmara cinematográfica tinha 60 metros de comprimento, seriam tiradas cêrca de 3.000 imagens do fenómeno - 500 em cada um dos contactos, com o intervalo de 0,12 s, o qual no eclipse de Ovar deu bom resultado" (Lobo, 1914).

Note-se que, apesar do estudo das contas de Baily ser o principal objectivo da expedição portuguesa, não era, contudo, o único. Pretendia-se igualmente

- cinematografar a variabilidade da corona - cinéliocronógrafo;

- fotografar a cor da corona - fotoheliógrafo;

- determinar os tempos de exposição que conviria adoptar para a fotografia das diferentes partes da corona - câmara fotográfica;

- fotografar o espectro da corona e o espectro relâmpago - espectroscópio + câmara fotográfica (LOBO 1914).

É evidente que, apesar de alguns dos instrumentos do observatório de Coimbra estarem datados, se procurou explorar as potencialidades dos meios disponíveis.

Em resumo, e contrariamente ao que AGUIAR escreveu recentemente (2009, p. 144), Costa Lobo tinha um programa científico bem definido, enquadrado nos temas de pesquisa da época que procurava contribuir para o desenvolvimento da astronomia.

Os membros da expedição portuguesa encontravam-se em Berlim em 1 de agosto de 1914, dia fatídico em que a Alemanha declarou guerra à Rússia, iniciando, assim, a Primeira Guerra Mundial. Obrigados a interromper a sua viagem, os membros da expedição portuguesa dirigiram-se para a Suíça, regressando posteriormente a Portugal. No dia 21 de Agosto, Costa Lobo limitou-se a observar um eclipse solar parcial no observatório astronómico da Universidade de Coimbra (LOBO 1914). Desconhecemos o destino dos instrumentos enviados para a Crimeia mas suspeitamos que foram devolvidos uma vez que o fotoheliógrafo se encontra no espólio do observatório astronómico da Universidade de Coimbra.

Outras expediçōes foram igualmente perturbadas pelo início da guerra. Em particular, a expedição alemã destinada à Crimeia, foi obrigada a regressar antes do início do eclipse.

\section{Nova TENTATIVA: O ECLIPSE DE 29 DE JUNHO DE 1927}

Nos anos seguintes o conflito teve, naturalmente, um impacto negativo na astronomia mundial, diminuindo as colaborações internacionais e, em particular, reduzindo as expedições destinadas à observação de eclipses solares.

Em Portugal, o fim do conflito pautou-se pela instabilidade política e social resultante, em parte, dos problemas económicos e financeiros que afectavam o país. Em consequência destas dificuldades e possivelmente dos esforços desenvolvidos para a instalação de um espectroheliógrafo no observatório de Coimbra, só em 1927 Costa Lobo voltou a organizar uma expedição de observação de um eclipse solar. A estação de observação portuguesa ficou localizada no norte de Inglaterra, no Stonyhurst College, sendo a curta duração da totalidade do eclipse aí observada, aproximadamente 20 segundos, contrabalançada pela acessibilidade do local. De novo, Costa Lobo pretendia cinematografar o eclipse por forma a verificar uma possível variação da 
luminosidade dos grãos de Baily devida à refracção dos raios solares nos gases densos existentes no fundo dos vales lunares. A obtenção de um filme da totalidade do eclipse, rodado entre quatro e oito imagens por segundo, permitiria ainda estudar a variabilidade da cromosfera e da corona. Duas câmaras cinematográficas foram acopladas a lentes para que a imagem do Sol, no filme, fosse aproximadamente igual a um centímetro de diâmetro. Os instrumentos com montagem equatorial foram instalados no terraço do colégio. A expedição era composta por Costa Lobo e pelo observador do observatório de Coimbra, José António Madeira (1896-1976), com apoio logístico dos professores e alunos do colégio (ANÓNIMO, 1927b; 1927c).

No dia do eclipse, segundo Costa Lobo,

\begin{abstract}
"Havia grandes rasgões nas nuvens, o Sol mostrava-se, a ansiedade aumentava e apreciava-se com o maior interesse a direcção e velocidade das nuvens, tudo estava dependente de um acaso. Uma nuvem densa encobriu o primeiro contacto, às 4 horas e 30 minutos (tempo universal), mas restava a parte importante, a totalidade, que devia decorrer desde as 5 horas, 21 minutos e 22 segundos, durante vinte e dois segundos precisos. Chegou o momento, o resultado era incerto mas a filmagem seguiu e só em Portugal, onde vieram revelar-se os "films", pode verificar-se que, embora não tivessem apanhado o fenomeno na sua parte mais interessante, tinhamos, em todo o caso cerca de 1:000 imagens em cada "film", perfeitamente nitidas, dando com grande rigor o momento do ultimo contacto e demonstrando, com grande numero de imagens obtidas por segundo, 40 num dos aparelhos e 20 no outro, as grandes vantagens que oferece o metodo cinematografico empregado scientificamente" (ANÓNIMO, 1927a).
\end{abstract}

A memória prometida dando conta detalhada dos trabalhos e resultados da expedição nunca chegou a ser publicada o que poderá indicar que, numa análise mais cuidada, as condições atmosféricas não terão permitido cumprir os objectivos da missão.

\title{
DisCUSSÃO E CONCLUSŌES
}

Poucos foram os filmes astronómicos realizados nos primeiros anos após o aparecimento da moderna câmara de filmar em 1895. A falta de eventos astronómicos adequados, isto é, suficientemente rápidos e brilhantes limitava a utilização da cinematografia como instrumento de registo. O interesse na observação do eclipse solar de 17 de Abril de 1912 e, porventura, as suas características, particularmente a sua curta duração, levaram a que pelo menos nove câmaras de filmar, dispersas por Portugal, Espanha, França, Bélgica e Alemanha, tenham sido utilizadas para capturar este fenómeno. Nunca anteriormente tantas câmaras tinham sido destinadas a registar um único evento astronómico. As condiçōes atmosféricas favoráveis permitiram a obtenção de vários filmes e, pela primeira, vez surgiu uma nova hipótese baseada exclusivamente nas imagens cinematográficas. A partir de um registo passível apenas de ser efectuado por uma máquina de filmar, Costa Lobo propôs uma hipótese inesperada, a existência de um achatamento da Lua. Hipótese esta que foi, no entanto, rapidamente esquecida pela comunidade internacional. 
No nosso entender, razões técnicas, científicas e humanas explicam este desfecho. A análise efectuada não era comum. Os artigos publicados anteriormente sobre observações cinematográficas limitavam-se a descrever o equipamento cinematográfico e/ou as imagens obtidas. É, aliás, neste género que se enquadram as comunicaçōes sobre os filmes do eclipse de 1912 anteriores à publicação do artigo de Costa Lobo nos Comptes Rendus. O resultado era inesperado e os autores dos dois artigos que apoiavam esta hipótese, Costa Lobo e Willaert, não possuíam, na altura, um currículo astronómico internacional. Foram apresentadas outras hipóteses alternativas para explicar as observaçóes, vindo a ser aceite a proposta do conceituado e extremamente influente Flammarion que mantinha a opinião prevalecente, isto é a Lua apresentar uma forma circular. Era impossível repetir, num intervalo de tempo razoável, a observação efectuada devido às características do eclipse. Por outro lado, do ponto de vista técnico, o meio utilizado dificultava a difusão dos resultados obtidos. Habitualmente apenas um pequeno número de imagens era impresso nos artigos. Por exemplo, o artigo de Costa Lobo nos Comptes Rendus reproduzia apenas sete pequenos fotogramas. Duplicar os filmes implicava custos e nem sempre era possível apresentá-los publicamente. Note-se, no entanto, que Costa Lobo apresentou o filme de 1912 no Congresso da União Astronómica Internacional, realizado em Cambridge, no Reino Unido, em 1925 (FOWLER 1925, p. 188). A sucinta nota que dá conta desta apresentação refere que o filme mostra a variação de intensidade das contas de Baily o que poderá indicar que Costa Lobo preparava já a expedição que viria a realizar dois anos mais tarde.

O interesse em obter registos cinematográficos não atingiu, pelo menos até à década de 30, o nível do eclipse de Abril de 1912.

Não sabemos por que razão Costa Lobo decidiu utilizar uma câmara de filmar na expedição de Ovar mas ao procurar cinematografar os eclipses solares de agosto de 1914 e de Junho de 1927 revela-nos não só a sua perseverança em resolver as questões levantadas em 1912, como mantém a confiança, apesar dos resultados, nas "grandes vantagens que oferece o metodo cinematografico empregado scientificamente" (ANÓNIMO 1927a). Costa Lobo tem igualmente lugar no reduzido clube daqueles que, entre 1895 e 1927, cinematografaram mais do que um evento astronómico. Registe-se que, nas expedições posteriores a 1912, existiam planos científicos com objectivos bem definidos que justificavam a observação cinematográfica o que nem sempre acontecia no estrangeiro. Pelas razōes expostas, consideramos de inteira justiça que Francisco Miranda da Costa Lobo seja reconhecido como um importante pioneiro da cinematografia astronómica internacional.

\section{Agradecimentos}

Os autores gostariam de agradecer a Emília Gomes por lhes ter chamado a atenção para as notícias do jornal $O$ Século relativa à observação de Costa Lobo do eclipse de 29 de Junho de 1927, bem como a gentil ajuda prestada pelo arquivista David Knight de Stonyhurst College. 


\section{REFERÊNCIAS}

AIRY, George Biddell - Autobiography of Sir George Biddell Airy. Cambridge: Cambridge University Press, 1896. AGUIAR, António Mota de - Os Estudos de Astronomia em Portugal de 1850 a 1950. Lisboa: Universidade de Lisboa. Faculdade de Ciências Sociais e Humanas, 2009. Tese de Doutoramento.

ANÓNIMO, O Estudo do Sol. «O Século». (25 Jul. 1927) p. 1, 6.

ANÓNIMO, Observations of the total solar eclipse, 1927 June 29 Stonyhurst College Observatory. «Monthly Notices of the Royal Astronomical Society». 87 (1927), p. 687-692.

ANÓNIMO, The total eclipse «The Stonyhurst Magazine» 19:270 (1927), p. 264-272.

ARAGO, François - Le Daguerrèotype. Comptes Rendus de l'Académie des Sciences de Paris. Vol. 9 (1839) p. 250-267.

BONIFÁCIO, Vitor; MALAQUIAS, Isabel; FERNANDES, João - The first astronomical hypothesis based upon cinematographical observations: Costa Lobo's 1912 evidence for polar flatenning of the Moon. Journal of Astronomical History and Heritage.13:2 (2010), p. 159-168.

CARVAllO, E. - Observation de l'éclipse de Soleil du 17 avril par l'École Polytechnique. Comptes Rendus de l'Ácadémie des Sciences de Paris. Vol. 154 (1912), p. 1072-1075.

ESPENAK, Fred. Eclipse Web Site http://hsfc.nasa.gov/eclipse/eclipse.html

FLAMMARION, Camille - Astronomie Populaire. Paris: C. Marpon et E. Flammarion, Éditeurs, 1880.

FLAMMARION, Camille - Éclipse de Soleil du 17 avril. Bulletin de la Société Astronomique de France. Vol. 26 (1912a), p. 486.

FLAMMARION, Camille - Forme de la Lune déduites des observations cinématographiques. Bulletin de la Société Astronomique de France. Vol. 26 (1912b), p. 321-324.

FOUCHÉ, M. - Observation de l'éclipse de Soleil du 17 avril par les élèves de l'École Polytechnique. Bulletin de la Société Astronomique de France. Vol. 26 (1912), p. 345-347.

FOWLER, A., ed. - Transactions of the International Astronomical Union - Second General Assembly held at Cambridge. London: Imperial College Bookstall, 1925.

JANSSEN, Jules - Passage de Vénus; Méthode pour obtenir photographiquement l'instant des contacts, avec les circonstances physiques qu'ils présentent. Comptes Rendus de l'Académie des Sciences de Paris. Vol. 76 (1873) p. 677-679.

KING, E. S. - Photographic observations of occultations. Annals of Harvard College Observatory. Vol. 59 (1912), p. $187-204$.

LAUNAY, Françoise; HINGLEY, Peter D. Jules Janssen's - "Revolver photographique" and its British derivative, "The Janssen slide". Journal for the History of Astronomy. Vol. 36 (2005), p. 57-79.

LOBO, Francisco Miranda da Costa - Eclipse central do sol. Revista da Universidade de Coimbra. Vol. 1, n. ${ }^{\circ} 1$ (1912a), p. 179-190.

LOBO, Francisco Miranda da Costa - Enregistrement cinématographique de l'éclipse du 17 avril, et forme un peu allongée du contour lunaire. Comptes Rendus de l'Académie des Sciences de Paris. Vol. 154 (1912b), p. 1396-1399.

LOBO, Francisco Miranda da Costa - L'éclipse de soleil du 17 avril 1912. Revista da Universidade de Coimbra. Vol. 1, n. 3 (1912c), p. 548-585.

LOBO, Francisco Miranda da Costa - O eclipse de 21 de agosto de 1914. Coimbra: Imprensa da Universidade, 1914.

LOBO, Francisco Miranda da Costa - Aspetos diversos apresentados pelos Grãos de Baily na observação do eclipse do sol de 17 de abril de 1912, feita em Ovar. In Congreso de Madrid - Asocioción Española para el Progresso de las Ciencias. Madrid: Impr. Eduardo Arias. p. 237-240.

LUCAS, D.; WILLAERT, Fernand - L'éclipse de soleil du 17 avril 1912 observée au Laboratoire du Collège N. -D. de la Paix à Namur. Revue des questions scientifiques. Vol. 72 (1912), p. 187-225.

OOM, Frederico - O Futuro Eclipse. O Instituto. Vol. 52 (1905), p. 487-490.

OOM, Frederico - Circunstâncias do Eclipse Anular-Total de 1912 abril 17 em Portugal. Lisboa: Imprensa Nacional, 1912.

PAOLANTONIO, Santiago - De Córdoba al Mar Negro. Relatos de una aventura científica. In MORGAN, Edgardo Ronal Minniti; PAOLANTONIO, Santiago - História de la Astronomia [Em linha]. [S.l.: s.n.] Disponível em WWW: URL:http://historiadelaastronomia.wordpress.com/documentos/de-cordoba-al-mar-negro/.

RODRIGUES, César Augusto de Campos - Observation de l'éclipse de Soleil 1912 Avril 16-17 à l'Observatoire de Lisbonne (Tapada). Astronomische Nachrichten. Vol. 191 (1912), p. 259-260.

RICCO, A. - Notizie. Missioni per l'eclisse solare totale del 21 agosto 1914. Memorie della Societa Degli Spettroscopisti Italiani. 2a Série. Vol. 3 (1914), p. 160-161.

TOSI, Virgilio - La vera nascita del cinema. Le origini del cinema scientifico [Filme]. [S.l.: s.n.], 2005. Documentário em DVD.

VLĖS, Fred - Remarques sur la forme de la Lune et du Soleil. Comptes Rendus de l'Académie des Sciences de Paris. Vol. 155 (1912), p. 545-547. 